\title{
13 Differences by Gender, Age and Other Variables
}

The present chapter explores differences in the content of genuine suicide notes by gender, age, marital status and the method chosen for suicide.

\subsection{The Suicide Notes of Men and Women}

There are strong and clear sex differences in suicidal behavior. Women attempt suicide more than do men, whereas men complete suicide more than do women (Canetto \& Lester, 1995). Women use different methods for suicide than do men, preferring medications more and hanging and firearms less (Lester, 1984). It is thought, perhaps erroneously, that the motives behind the suicidal act differ, with women choosing suicide over love crises and men for achievement-oriented crises (Canetto, 1992-1993).

Despite these differences, studies of the suicide notes left by women and men have identified few differences. In an extensive study, Leenaars (1988b) found no differences in content, as have many other studies (Lester, 1989; Lester \& Hummel, 1980; Lester \& Heim, 1992; Lester \& Linn, 1997; Linn \& Lester, 1996). In contrast, Black (1989) found more indications of depression, self-hostility, confusion and despondency over the death of others in the suicide notes of women, while Lester and Reeve (1982) found that notes from women had fewer negative emotions but were more disorganized. All of these studies used judges to rate the suicide notes, a technique which can introduce subjectivity and unreliability in the judgments. The present chapter applies the objectivity proved by the LIWC to the analysis of suicide notes.

\subsubsection{Samples}

(1) Forty suicide notes from completed suicides from a town in Germany. There were 20 men and 20 women whose mean age was 35.5 years $(S D=18.8)$. The men and women did not differ in age.

(2) Forty-eight suicide notes from completed suicides from a town in the United States. There were 34 men and 14 women whose mean age was 43.2 years $(S D=17.5)$. The men and women did not differ in age.

(3) Two hundred and sixty one suicide notes from completed suicides in Tasmania, Australia: There were 195 men and 65 women with one subject with missing data. Their mean age was 41.8 yrs. $(S D=17.1)$. The men and women did not differ in age. 


\subsubsection{Results}

The results are shown in Table 13-1.

Tab. 13.1: Sex differences in the content of suicide notes

\begin{tabular}{|c|c|c|c|}
\hline & Germany $n=40$ & America $n=48$ & Australia $n=260$ \\
\hline Word count & $0.44^{* *}$ & -0.22 & 0.01 \\
\hline Unique words & $-0.49^{\star \star \star}$ & 0.17 & -0.03 \\
\hline Words in dictionary & 0.10 & $0.29^{*}$ & $-0.15^{*}$ \\
\hline Pronouns & 0.06 & 0.13 & $-0.17^{\star *}$ \\
\hline First person singular & -0.22 & 0.11 & $-0.16^{\star \star}$ \\
\hline First person plural & 0.18 & 0.08 & $-0.16^{* *}$ \\
\hline Total first person & -0.20 & 0.12 & $-0.18^{\star *}$ \\
\hline Negation & $-0.48^{\star *}$ & -0.07 & $-0.17^{\star \star}$ \\
\hline Articles & 0.22 & 0.12 & $0.18^{\star *}$ \\
\hline Numbers & 0.10 & $-0.28^{\star}$ & $0.14^{*}$ \\
\hline Positive feelings & -0.02 & 0.17 & $-0.13^{\star}$ \\
\hline Cognit9ve processes & $-0.39^{\star}$ & 0.14 & $-0.14^{\star}$ \\
\hline Insight & $-0.31 \#$ & 0.04 & $-0.15^{\star}$ \\
\hline Discrepancies & -0.28 & 0.03 & $-0.16^{\star}$ \\
\hline Tentative & $-0.35^{\star}$ & -0.01 & -0.05 \\
\hline Senses & 0.04 & $-0.28 \#$ & 0.04 \\
\hline Hearing & 0.10 & $-0.29^{\star}$ & -0.01 \\
\hline Other refs to people & $0.30 \#$ & 0.01 & -0.09 \\
\hline Friends & $0.30 \#$ & $-0.27 \#$ & 0.04 \\
\hline Time & $0.27 \#$ & 0.05 & -0.01 \\
\hline Present tense verbs & 0.08 & 0.04 & $-0.23^{\star \star \star}$ \\
\hline Up & $-0.27 \#$ & -0.13 & 0.01 \\
\hline Down & $0.32^{\star}$ & -0.09 & 0.09 \\
\hline Inclusive & $0.27 \#$ & 0.09 & -0.01 \\
\hline Money & $0.29 \#$ & 0.20 & 0.04 \\
\hline Sleep & 0.22 & $-0.26 \#$ & $-0.10 \#$ \\
\hline
\end{tabular}

${ }^{*}$ two-tailed $p<.05, * *$ two-tailed $p<.01,{ }^{* \star *}$ two-tailed $p<.001$, \# trend (two-tailed $p<0.10$ )

\subsubsection{German Sample}

Seven significant associations were found: men wrote longer notes, with fewer unique words, fewer negations, less mention of cognitive mechanism (such as cause, 
know, ought), fewer insight words (such as think, know, consider), fewer tentative words (such as maybe, perhaps), and more words concerned with "down" (such as down, below, under). Another eight associations showed trends: the men used few discrepancy words (such as should, would, could), communication words (such as talk, share, converse) and words concerned with "up", but had more references to people, friends, time, inclusion (such as with, and, include), and money.

Overall, the notes of men were more concerned with mentions of others, including friends, and less concerned with causation, and so the notes of the men seemed to be less concerned with explaining the reasons for their suicide and more concerned with communicating with others.

\subsubsection{American Sample}

Only three significant differences were found, no more than would be expected on the basis of chance with so many variables. The women used numbers more, words related to hearing more, and fewer dictionary words. These differences have little psychological significance.

\subsubsection{Australian Sample}

Thirteen significant differences were found between the content of the notes from men and women. The notes from women had a higher percentage of words found in the dictionary, pronouns, "I," "we," references to the self, negations, positive feelings, references to cognitive processes, insight words, discrepancy words (such as should, would and could), and present tense verbs, and a lower percentage of articles (such as a, an, the), and numbers.

\subsubsection{Comment}

The results of the study of German suicide notes differed greatly from those of American suicide notes, indicating perhaps a lack of generality in the results. These two samples were small, and so the results from the much larger Australian sample may be more meaningful. In this Australian sample, women were more concerned with themselves and others and with reasons for their suicide, similar to the results from the German suicide notes. It may be that the notes from men contained more instructions and were less personal. At least two of the three samples agreed for the categories of negations, cognitive mechanisms and insight, and sleep, with men having less of this content than did the women. Since previous research had identified few differences between the suicide notes from men and women, the present analysis provides hypotheses for future research, which clearly need to be tested using large samples. 


\subsection{Differences across the Life Span}

Leenaars (1989) reviewed research on differences in the psychodynamics of suicide by age and the extent to which these differences are reflected in the suicide notes that people write. The suicides of young people are more often motivated by interpersonal conflicts while the suicides of the elderly are more often motivated by internal events, in particular depression and medical illnesses. The suicide notes of younger people more often have inward-directed anger, and the content is more harsh and self-critical. Leenaars's own study found more inward-directed aggression, unsatisfied needs, self-punishment and interpersonal conflicts in the notes of younger adults (aged 18-25) as compared to older adults (aged 55-77).

To examine differences by age, the same samples as those used above were used.

\subsubsection{Results}

\subsubsection{German Sample}

Only four significant associations were found for age (see Table 13-2): older people used more prepositions, more words concerned with communication, more future tense verbs, and more words concerned with space.

\subsubsection{American Sample}

Only three significant differences were found for age (see Table 13-2): older people used more long words (more than 6 letters) and religious words, and a smaller proportion of words concerned with negative emotions.

\subsubsection{Australian Sample}

Twenty-four significant differences in the content of the notes were found by age (see Table 13-2). The notes of older note writers had fewer words, fewer words per sentence, a lower percentage of words found in the dictionary, pronouns, "I," references to the self, "you," articles, positive feelings, anxiety or fear, references to cognitive processes, causation, tentative words (such as maybe and perhaps), seeing, social processes, references to people, references to family, present tense verbs, exclusive words (such as but and except), sports, and sex and sexuality, and a higher percentage of references to the body and unique words. 


\subsubsection{Discussion}

Clearly, having a larger sample (from Australia) increased the chances of finding significant associations. The major differences in the Australian sample were that the older suicides were less concerned with emotions (positive and negative), with explanations for their suicide, and with social relationships. They did mention the body more, most likely concerning illness and pain (although these categories are not assessed

Tab. 13.2: Correlations over age

\begin{tabular}{|c|c|c|c|}
\hline & Germany $n=40$ & America $^{43} n=45$ & Australia $n=258$ \\
\hline Word count & -0.14 & 0.02 & $-0.13^{\star}$ \\
\hline Words per sentence & 0.15 & -0.23 & $-0.21^{\star \star \star}$ \\
\hline Unique words & 0.11 & 0.10 & $0.21^{\star \star \star}$ \\
\hline Words in dictionary & -0.04 & -0.16 & $-0.17^{\star \star}$ \\
\hline Words with $6+$ letters & 0.15 & $0.47^{\star \star \star}$ & 0.07 \\
\hline Pronouns & -0.22 & 0.04 & $-0.29^{\star \star \star}$ \\
\hline First person singular & -0.20 & 0.01 & $-0.24^{\star \star \star}$ \\
\hline Total first person & -0.17 & 0.01 & $-0.25^{\star \star \star}$ \\
\hline Total second person & -0.02 & 0.05 & $-0.16^{\star}$ \\
\hline Total third person & -0.02 & -0.24 & $-0.12 \#$ \\
\hline Articles & 0.23 & -0.07 & $-0.17^{\star \star}$ \\
\hline Prepositions & $0.40^{\star}$ & 0.03 & $0.11 \#$ \\
\hline Positive feelings & 0.18 & 0.07 & $-0.16^{\star}$ \\
\hline Negative emotions & 0.03 & $-0.33^{\star}$ & 0.02 \\
\hline Anxiety & -0.07 & 0.09 & $-0.14^{\star}$ \\
\hline Anger & $-0.29 \#$ & -0.23 & 0.01 \\
\hline Cognitive processes & -0.21 & -0.11 & $-0.25^{\star \star \star}$ \\
\hline Causation & -0.09 & 0.01 & $-0.24^{\star \star \star}$ \\
\hline Insight & -0.08 & 0.03 & $-0.12 \#$ \\
\hline Discrepancies & -0.08 & 0.06 & $-0.27^{\star \star \star}$ \\
\hline Inhibition & -0.25 & $-0.26 \#$ & 0.02 \\
\hline Tentative & -0.03 & 0.13 & $-0.16^{\star}$ \\
\hline Seeing & 0.15 & -0.02 & $-0.12 \#$ \\
\hline Social processes & 0.10 & 0.05 & $-0.21^{\star \star \star}$ \\
\hline
\end{tabular}

43 Three suicides had missing data for age. 
Tab. 13.2: Correlations over age

\begin{tabular}{|c|c|c|c|}
\hline & Germany $n=40$ & America $^{43} n=45$ & Australia $n=258$ \\
\hline Communication & $0.33^{*}$ & 0.21 & -0.07 \\
\hline Other refs to people & 0.01 & 0.01 & -0.20 ** \\
\hline Family & -0.01 & 0.16 & $-0.12^{\star}$ \\
\hline Past tense verbs & -0.25 & $-0.28 \#$ & -0.07 \\
\hline Present tense verbs & -0.25 & 0.01 & $-0.17^{\star \star}$ \\
\hline Future tense verbs & $0.38^{*}$ & 0.06 & -0.08 \\
\hline Space & $0.42^{\star \star}$ & 0.16 & 0.03 \\
\hline Up & $0.28 \#$ & 0.14 & 0.07 \\
\hline Down & 0.18 & $0.25 \#$ & -0.01 \\
\hline Inclusive & 0.12 & $-0.29 \#$ & -0.02 \\
\hline Exclusive & -0.21 & -0.07 & $-0.22^{\star \star \star}$ \\
\hline Occupations & -0.05 & $-0.26 \#$ & 0.02 \\
\hline Achievements & -0.16 & $-0.25 \#$ & 0.06 \\
\hline Sports & 0.22 & -0.04 & $-0.13^{*}$ \\
\hline Religion & $0.27 \#$ & $0.33^{*}$ & 0.09 \\
\hline Body & 0.23 & 0.14 & $0.14^{\star}$ \\
\hline Sexual & -0.13 & -0.16 & $-0.16^{\star \star}$ \\
\hline Sleep & 0.19 & 0.20 & $0.11 \#$ \\
\hline Swearing & $-0.29 \#$ & 0.18 & -0.08 \\
\hline
\end{tabular}

${ }^{*}$ two-tailed $p<.05,{ }^{\star \star}$ two-tailed $p<.01,{ }^{* \star \star}$ two-tailed $p<.001, \#$ trend (two-tailed $p<0.10$ )

by the LIWC). The notes of the older adults were shorter and probably concerned with instructions (although, again, instructions are not directly assessed by the LIWC).

\subsection{Differences by Method of Suicide}

Some of the samples of suicide notes analyzed above had data also on the method used for suicide. In the past, research has not identified many psychological differences between those using different methods for suicide. For example, Lester (1971c, 1971d) failed to find differences in the content of suicide notes of those using violent versus non-violent methods for suicide. Lester (1988b) found no differences in the MMPI scores of those using firearms and those using overdoses for suicide. On the other hand, Lester and Beck (1980-1981) found that attempted suicides who used cutting (versus medications) had less suicidal intent, different stressful life events 
(for example, more often recent legal problems), more severe psychiatric disturbance and more alcohol abuse.

Correlates of choice of method for suicide were explored in these three samples of suicide notes.

\subsubsection{Results}

\subsubsection{German Sample}

Those using hanging (coded as $1, \mathrm{n}=12$ ) versus solids, liquids or gas (coded as $0, \mathrm{n}=$ 17) used fewer causation words, leisure words, words connected with the home, and words concerned with death (see Table 13-3).

\subsubsection{American Sample}

Comparing those using pills (coded as $1, n=19$ ) versus firearms (coded as $0, n=15$ ), those using firearms scored lower on the use of words concerned with discrepancies (such as would, should and could) (see Table 13-3).

Tab. 13.3: Difference in suicide note content by method

\begin{tabular}{lll}
\hline & Germany $\mathrm{n}=\mathbf{2 9}$ & America $\mathrm{n}=\mathbf{3 4}$ \\
\hline Words per sentence & $-0.33 \#$ & 0.14 \\
Cognitive processes & $-0.32 \#$ & 0.05 \\
Causation & $-0.37^{\star}$ & $0.29 \#$ \\
Discrepancies & -0.28 & $-0.46^{\star \star}$ \\
Present tense verbs & $-0.32 \#$ & 0.01 \\
Leisure & $-0.44^{\star}$ & 0.29 \\
Home & $-0.38^{\star}$ & 0.17 \\
Death & $-0.42^{\star}$ & 0.08 \\
\hline * two-tailed $\mathrm{p}<.05,{ }^{* *}$ two-tailed $\mathrm{p}<.01, \#$ trend (two-tailed $\left.\mathrm{p}<0.10\right)$ \\
\hline
\end{tabular}

\subsubsection{Australian Sample}

In this large sample, three methods were used frequently for suicide: solids and liquids $(n=63)$, guns $(n=98)$ and gas $(n=42)$. These three groups differed on only seven variables (see Table 13-4). Those using guns had a lower percentage of words concerned with sadness/depression and future tense verbs. Those using gas had more 
references to friends, words concerned with "down," exclusion words (such as but and except), occupation and achievement. Those using solids and liquids had the most references to sadness/depression and future tense verbs.

\subsubsection{Discussion}

These results are interesting because they suggest that the choice of method for suicide may be related to important psychodynamic characteristics of the individual and, therefore, provide clues to the motives and causes of the suicide. For example, in the Australian sample, depression was more common in those using solids and liquids than in those using guns, suggesting that those using guns may be in an acute crisis (and perhaps acting impulsively), whereas those using solids and liquids may more often have a chronic psychiatric condition. These hypotheses obviously require further research, but they suggest the relevance of choice of method for suicide and possible preventive measures. ${ }^{44}$

Tab. 13.4: Differences by method for the Australian suicide notes- means scores shown

\begin{tabular}{|c|c|c|c|}
\hline & Solids/liquids & Guns & Gas \\
\hline Articles* & 2.9 & 3.7 & 4.2 \\
\hline Future tense verbs* & 2.3 & 1.4 & 2.1 \\
\hline Down* & 0.1 & 0.1 & 0.5 \\
\hline Exclusive $^{\star \star}$ & 1.9 & 2.3 & 3.3 \\
\hline Occupations* & 0.7 & 0.8 & 1.5 \\
\hline Achievements* & 0.4 & 0.5 & 1.1 \\
\hline Sad\# & 0.51 & 0.26 & 0.38 \\
\hline Friends\# & 0.10 & 0.10 & 0.60 \\
\hline
\end{tabular}

44 For a comparison of those using different methods for suicide in this Australian sample on demographic and other personal variables, see Haines, Williams and Lester (2010). 


\subsection{Marital Status}

Hitherto, there has been no research on differences in the content of suicide notes by marital status. Do single, married, divorced and widowed suicides write different suicide notes? This question was explored in these samples of suicide notes.

\subsubsection{Results}

\subsubsection{German Sample}

Comparing the married suicides (coded as $1, \mathrm{n}=19$ ) with the single individuals (coded as $0, n=14$ ) there were no significant associations with marital status (see Table 13-5). Since marital status was associated with age and sex, partial correlation coefficients were calculated controlling for age and sex, and the results remained pretty much the same.

Tab. 13.5: Differences by marital status

\begin{tabular}{lllll}
\hline & Germany $(\mathrm{n}=33)$ & & America $(\mathrm{n}=32)$ & \\
& $\mathrm{r}$ & partial $\mathrm{r}$ & $\mathrm{r}$ & partial $\mathrm{r}$ \\
\hline Pronouns & -0.09 & -0.04 & $0.36^{\star}$ & $0.31 \#$ \\
Total third person & -0.28 & -0.31 & 0.01 & 0.10 \\
Numbers & -0.12 & -0.04 & $-0.32 \#$ & -0.30 \\
Negative emotions & -0.17 & 0.03 & $-0.35 \#$ & -0.30 \\
Sad & 0.06 & 0.01 & $-0.44^{*}$ & $-0.44^{*}$ \\
Senses & 0.16 & -0.02 & $-0.38^{*}$ & $-0.34 \#$ \\
Feeling & 0.01 & 0.03 & $-0.34 \#$ & $-0.39^{*}$ \\
Communication & 0.27 & 0.03 & -0.13 & -0.23 \\
Present tense verbs & -0.22 & 0.05 & $0.30 \#$ & 0.25 \\
Inclusive & 0.23 & -0.15 & $-0.31 \#$ & -0.26 \\
Motion & 0.15 & 0.00 & $0.42^{\star}$ & $0.34 \#$ \\
Occupations & 0.25 & 0.12 & $-0.37^{*}$ & -0.31 \\
Achievements & 0.09 & 0.19 & $-0.38^{*}$ & $-0.36 \#$ \\
Leisure & -0.29 & -0.28 & -0.11 & -0.11 \\
Home & -0.25 & -0.28 & $-0.34 \#$ & $-0.36 \#$ \\
Death & -0.18 & $-0.47^{*}$ & $-0.31 \#$ & $-0.33 \#$ \\
Sleep & -0.01 & 0.24 & -0.05 & -0.08 \\
Swearing & -0.27 & -0.10 & 0.09 & -0.03 \\
\hline * two-tailed $p<.05, * *$ & two-tailed $\mathrm{p}<.01, \#$ trend (two-tailed $\mathrm{p}<0.10)$ & \\
\hline
\end{tabular}




\subsubsection{American Sample}

Comparing the suicide notes from married individuals (coded as $1, \mathrm{n}=19$ ) with those from the single suicides (coded as $0, \mathrm{n}=13$ ), six significant differences were identified (see Table 13-5). The notes from married individuals had more pronouns and references to motion, and fewer references to sadness, the senses, occupation and achievement. Since marital status was associated with both age and sex, partial correlation coefficients were calculated controlling for age and sex, and the results remained similar.

\subsubsection{Australian Sample}

As before, comparing the married and single suicides and the married and divorced suicides revealed many more differences than in the smaller German and American samples (see Table 13-6). The married suicides wrote shorter notes than the never married suicides, had more positive emotions and fewer negative emotions, and were less concerned with explaining their behavior. Compared to the divorced suicides, the married suicides again wrote shorter suicide notes but did not substantially in the emotions expressed. This might be because the married suicides were often in the midst of marital conflict, and so were concerned with similar issues as the divorced suicides. The married suicides were again somewhat less concerned with explaining their behavior.

\subsubsection{Discussion}

Since this is the first study of the suicides notes of single, married and divorced suicides, it may provide hypotheses for future research. As before, more significant findings were identified with the larger (Australian) sample, emphasizing the importance of sample size in this type of research.

\subsubsection{Comments}

The analyses in this chapter have identified several interesting hypotheses for future research. Whereas previous research had identified few differences between the suicide notes of men and women, the present analysis of the Australian sample identified a number of interesting differences, such as more positive emotions and references to cognitive processes in the suicide notes of women. Differences were also found by age, marital status and the method chosen for suicide.

Previous research was constrained by the small sample sizes, but the Australian sample of 261 suicides notes demonstrates that obtaining a large sample of suicide notes produces results that are significant and, because of the large sample size, 
likely to be more reliable results. Future research on suicide notes should make an effort to obtain large sample sizes. Sample sizes of wenty or thirty suicide notes are not enough for meaningful research.

Tab. 13.6: Differences by marital status for the Australian sample

\begin{tabular}{|c|c|c|c|c|}
\hline & \multicolumn{2}{|c|}{$\begin{array}{l}\text { Married versus Single } \\
\text { (coded as } 1 \text { versus } 0 \text { ) } \\
n=168\end{array}$} & \multicolumn{2}{|c|}{$\begin{array}{l}\text { Married versus Divorced } \\
\text { (coded as } 1 \text { versus } 0 \text { ) } \\
n=158\end{array}$} \\
\hline & $\begin{array}{l}\text { Pearson } \\
\text { correlations }\end{array}$ & $\begin{array}{l}\text { Partial } \\
\text { correlations }\end{array}$ & $\begin{array}{l}\text { Pearson } \\
\text { correlations }\end{array}$ & $\begin{array}{l}\text { Partial } \\
\text { correlations }\end{array}$ \\
\hline Word count & $-.21^{\star \star}$ & $-.16^{\star}$ & $-.29 * \star \star$ & 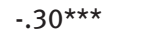 \\
\hline Words per sentence & $-.22^{\star \star}$ & -.12 & $-.18^{\star}$ & $-.18 *$ \\
\hline Unique words & $.23^{\star \star}$ & $.16^{\star}$ & $.31^{\star \star \star}$ & $.32^{\star \star \star}$ \\
\hline Total second person & .07 & $.18^{*}$ & .03 & .05 \\
\hline Total third person & -.07 & -.04 & $-.26 * \star \star$ & $-.25^{\star \star}$ \\
\hline Affect & $.16^{\star}$ & $.13 \#$ & .08 & .07 \\
\hline Positive emotions & $.20^{\star \star}$ & $.18^{\star}$ & .12 & .11 \\
\hline Positive feelings & $.19 *$ & $.24^{\star \star}$ & .13 & $.15 \#$ \\
\hline Anxiety & $-.13 \#$ & -.07 & .09 & .05 \\
\hline Sad & $-.13 \#$ & -.10 & $-.18^{\star}$ & $-.19 \star$ \\
\hline Cognitive processes & $-.20^{\star}$ & $-.15 \#$ & -.09 & $-.16^{\star}$ \\
\hline Causation & $-.29 * \star \star$ & $-.21 \star \star$ & $-.19^{\star}$ & $-.19 \star$ \\
\hline Discrepancies & $-.16^{\star}$ & -.10 & -.13 & $-.18^{\star}$ \\
\hline Social processes & .07 & $.19 *$ & -.07 & -.06 \\
\hline Other refs to people & .07 & $.16^{\star}$ & -.06 & -.05 \\
\hline Humans & $.17^{\star}$ & $.22^{\star \star}$ & -.13 & -.11 \\
\hline Present tense verbs & $.15 \#$ & $.19^{\star}$ & $.17^{\star}$ & $.14 \#$ \\
\hline Up & $.16^{\star}$ & $.14 \#$ & $.14 \#$ & $.14 \#$ \\
\hline Inclusive & -.07 & -.09 & -.11 & $-.14 \#$ \\
\hline Religion & $.15 \#$ & $.13 \#$ & -.02 & -.04 \\
\hline Death & -.11 & $-.13 \#$ & -.09 & -.09 \\
\hline Physical states & $.15 \#$ & $.16^{\star}$ & $.13 \#$ & $.17^{\star}$ \\
\hline Sexual & $.17^{\star}$ & $.22^{\star \star}$ & $.14 \#$ & $.16 \#$ \\
\hline Eating & .08 & .06 & $.13 \#$ & $.14 \#$ \\
\hline Grooming & -.12 & $-.18^{\star}$ & -.07 & -.08 \\
\hline Swearing & .07 & $.13 \#$ & -.02 & .01 \\
\hline
\end{tabular}

